\title{
Aproximaciones a una metamorfosis del sujeto estético contemporáneo
}

\author{
Carlos Miranda Mas \\ Universidad de Málaga
}

PALABRAS CLAVE: Estética/ Teoría del Arte

"El problema a la vez político, ético, social y filosófico que se nos plantea hoy no es intentar liberar al individuo del Estado y de sus instituciones, sino liberarnos nosotros del Estado y del tipo de individualización que le está vinculada. Hay que promover nuevas formas de subjetividad rechazando el tipo de individualidad que se nos ha impuesto durante siglos". Michel Foucault.

\section{RESUMEN}

El sujeto estético contemporáneo es un objeto ambiguo y real. Un objeto que vamos a emplear como instrumento de comprensión de un muy especial fenómeno del arte. Se formulan unos principios que nos permitan comprender algunas de las razones de lo que venimos tipificando como arte invisible.

\section{ABSTRACT}

The contemporaneous aesthetic subject is an ambiguous and real object. An object that we are going to use as instrument of comprehension of a very special art phenomenon. Some principles which let us understand some of the reasons which we are typifying as invisible art are being formulated.

\section{INTRODUCCIÓN: UN ARTE INVISIBLE.}

Huyamos de la definición. Con estas líneas no pretendemos concluir qué, o quién, sea ese sujeto estético contemporáneo aludido en el título de las mismas. Este propio título nos avisa ya de que estamos planteando no una disección sino un acercamiento, una deriva alrededor de un objeto tan ambiguo como inasible, tan difuso como, sin embargo, real. Un objeto que vamos a emplear como instrumento de comprensión de un muy especial fenómeno del arte. Nos dedicaremos aquí, pues, a

* MIRANDA MAS, Carlos: "Aproximaciones a una metamorfosis del sujeto estético contemporáneo", Boletín de Arte $\mathrm{n}^{\circ} 28$, Departamento de Historia del Arte, Universidad de Málaga, 2007, págs.571-597. 
encontrar unos principios, específicamente en el hombre contemporáneo, que nos permitan comprender algunas de las razones de lo que venimos tipificando como arte invisible, un modo de aparición artística que nos parece muy significativo de los profundos movimientos que ha experimentado nuestra cultura desde su inaugural modernidad, y que proyecta en el futuro todo un abanico de posibilidades de un arte que ya no se limite a sus espacios tradicionales de exposición e intercambio.

Aclaremos, por tanto, que cuando empleamos la expresión arte invisible lo hacemos para hablar de toda una serie de manifestaciones artísticas contemporáneas que no aparecen como tales, esto es, no se muestran como obras de arte, sino como simples imágenes en un paisaje mediático que emplean como territorio en el que camuflarse. Y, paradójicamente, han de hacerlo así para actuar de modo efectivo en él: su sentido marcadamente crítico con respecto a la praxis vital a la que se refieren no encuentra lugar en los habituales espacios para el arte, pues éstos ya están reconocidos y marcados, precisamente, como escenarios del arte, esto es, como ámbitos eminentemente ficticios. Al contrario, lo que se pretende desde estas actuaciones es incidir de forma directa y, sobre todo, no avisada, en un sujeto contemporáneo que ya no se halla en posición de haber ido a ver una obra de arte, sino que va a encontrarse con una imagen -repetimos, que no reconoce como artísticaque provoca un conflicto en la propia relación de este sujeto con los principios de realidad que le permiten leer el mundo en torno. Ejemplos de este modo de funcionamiento artístico pueden aportarse muchísimos, mas uno que nos resultará particularmente cercano es el trabajo de Rogelio López Cuenca (Nerja, 1959), del cual traemos a estas líneas varias intervenciones urbanas.

Acerquémonos, pues, a este modo de comprender la acción del arte en la sociedad pensando la figura a la cual se dirige. Pensemos ese sujeto de un arte invisible.

\section{ACERCA DE UN CONCEPTO DE SUJETO.}

Ante todo, vamos a tratar de realizar una reconsideración de esos usos que damos al término "sujeto", pues, desde que se instituyen la estética, la historia del arte o la crítica de arte, esto es, las disciplinas teóricas en las que se manifiesta la naciente autonomía del arte, hasta el momento actual en el que tratamos la cuestión, el protagonista del proceso de conocimiento que atribuimos al arte ha experimentado, según veremos, no pocas modificaciones. No podremos, pues, comenzar sin señalar que cuando empleamos el término "sujeto" nos estamos refiriendo a una acepción del mismo que lo define como sujeto cognoscente. No se trata, pues, ni de un sujeto lógico, ni de un sujeto ontológico, como claramente distingue Ferrater Mora en su Diccionario de Filosofía: en él, define, pues, al sujeto cognoscente como sigue: 
"[...] Desde el punto de vista gnoseológico, el sujeto es el sujeto cognoscente, el que es definido como "sujeto para un objeto" en virtud de la correlación sujeto-objeto que se da en todo fenómeno de conocimiento y que, sin negar su mutua autonomía, hace imposible la exclusión de uno de sus elementos"1.

De esta forma, nos conviene dejar aclarada la cuestión de que, cuando hacemos uso del término "sujeto" en este texto, salvo que se indique lo contrario, estamos remitiéndonos a dicha definición.

Nuestro sujeto de conocimiento, pues, va a elaborar ese conocimiento, como estábamos diciendo, a partir de un contexto en el que experimenta una relación con su objeto, con el arte. Y, dado que el arte se ha establecido tradicionalmente como el referente concreto de la disciplina estética, hablaremos de un sujeto estético. Más particularmente, vamos a tratar las causas de esa relación del sujeto estético con las obras de arte invisible que aquí proponemos. Por tanto, antes de estar en condiciones de analizar esta relación concreta, habremos de recorrer el camino que nos muestra algunas transformaciones de esta figura del sujeto a lo largo del tiempo en el que hemos acotado su existencia, que no es otro que el de lo que nuestra cultura denomina como su modernidad.

En efecto, no podemos hablar de cambios y transformaciones en la esfera de las representaciones sin tener en cuenta a quién van dirigidas, pues los códigos que se orquestan no son más que instrumentos de comunicación de unos sujetos que interpretan según unos cánones culturales globales, dependientes de la complejidad toda de su tiempo, más allá, por tanto, de particularidades propias de la especificidad de los lenguajes del arte. Y si, por ejemplo, en los siglos XVIII y XIX podemos teorizar el sujeto burgués, como producto por excelencia de la llustración, hoy podremos decir que ese sujeto ya no existe como tal. Esta figura ha desarrollado su existencia social a lo largo de la modernidad y, sobre todo, de lo que hemos llamado postmodernidad, de manera que muchas de sus cualidades originarias van a resultar radicalmente transformadas en vías de constituir una forma alterada de la misma.

\footnotetext{
1 El empleo del término "sujeto" puede producir graves inexactitudes, derivadas, precisamente, de la confusión entre sujeto lógico, sujeto ontológico y sujeto cognoscente, que es el que hemos definido como adecuado para nuestros propósitos. En la obra de Ferrater Mora nos encontramos también la explicación, entre otros, del sujeto lógico y el sujeto ontológico del siguiente modo:

"[...] Desde el punto de vista lógico, aquello de que se afirma o niega algo. El sujeto se llama entonces "concepto-sujeto" y se refiere a un objeto que es. [...] desde el punto de vista ontológico, el objeto-sujeto. Este objeto-sujeto es llamado también con frecuencia objeto, pues constituye todo lo que puede ser sujeto de un juicio. Las confusiones habituales entre "sujeto" y "objeto", los equívocos a que ha dado lugar el empleo de estos términos pueden eliminarse mediante la comprensión de que ontológicamente todo objeto puede ser sujeto de juicio [...] En efecto, este último puede no ser exclusivamente [...] el ser individual, sino que puede ser cualquiera de las realidades clasificadas por la teoría del objeto (un ser real, un ser ideal, una entidad metafísica, un valor)“.
} 
Una sintomática alteración -a la que volveremos insistentemente en las líneas que siguen- que nos revelará importantes razones de operación del arte invisible, precisamente porque éste responde a unas prácticas sociales que derivan, a su vez, de procesos específicos de modificación en los modos de existir en la cultura que habitamos. En este sentido, veremos cómo se produce un fenómeno de, sin embargo, progresiva distinción entre cultura y sociedad que va a propiciar no pocas contradicciones a la institución artística moderna.

Así mismo, habremos también que distinguir hasta qué punto ese sujeto burgués es el receptor ideal de las obras de arte de su tiempo, y cuál es la evolución que observamos en su relación con las mismas, o bien, de los discursos artísticos respecto a éste.

Por lo tanto, y siempre en la perspectiva de análisis que estamos realizando del arte actual hacia su concreción en un modo particular como es el del arte invisible, vamos a acercarnos al devenir de este sujeto que se instituye, en expresión de Marchán Fiz, como condición para el inicial compromiso de la estética con el proyecto de emancipación humana. De cualquier forma, hemos de señalar que esta aproximación no la hemos planteado nunca como recorrido de una línea de historia del sujeto estético contemporáneo, sino como una acumulación de visitas discrecionales a sus condiciones y determinaciones. La ambigüedad y la complejidad del mismo así lo requieren. No deseamos abarcar una figura esencialmente contradictoria como una unicidad que, irremediablemente, nos lleve a deducir su constancia en el tiempo, cuando lo que, precisamente, demanda este estudio es la asimilación de sus mutaciones, de los puntos de fuga respecto de aquella pretérita identidad fuerte fundada por la llustración que apunten procedencias de nuestro arte invisible. El recurso narrativo, por tanto, de ir hacia delante y hacia atrás en el tiempo, los modos de deriva que empleamos, no hacen sino remitir al modo como se ha llevado a cabo el propio proceso de su investigación, aquel que, al mirar en el espejo del pasado, busca lo que ya no está en él, pues será sabiendo el porqué de tales ausencias que podamos sospechar nuestras razones actuales.

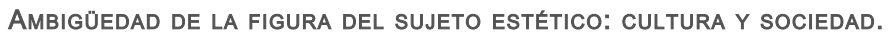

Se suele identificar la clase de sujeto que surge de la expansión del pensamiento racionalista a través de la llustración, con el sujeto moderno, y resulta frecuente, también, comprenderlo como fundamento de la disciplina estética. Como apunta Valeriano Bozal, "el origen de la estética moderna está en el origen del sujeto moderno, es una de sus partes"2. No obstante, es común que las cosas no resulten tan simples como parecen comprenderse en un primer instante, y esto ocurre también en nuestro caso. El sujeto que tipificamos como sujeto moderno se revela 
pronto como inagotable fuente de ambigüedades, y tomar conciencia de esta condición del mismo será, quizás, lo que más útil nos resulte en este punto. El escritor Justo Navarro nos va a servir, a propósito de un hermoso texto con el que introduce a una obra del novelista norteamericano Paul Auster (que antes fue traductor), para apreciar, desde un refrescante punto de vista -un tanto distanciado de la jerga estética-, este fenómeno, que nos parece bien significativo, con objeto de aproximarnos a las raíces del conflicto inherente a esa clase de sujeto que podemos entender como sujeto estético:

[...] "Al traductor Paul Auster lo asombraba el misterio de la traducción. Un hombre llamado Paul Auster lee en Nueva York un libro escrito en francés y luego escribe ese mismo libro en inglés. Supongamos que traduce las notas que Mallarmé escribió junto al lecho de muerte de su hijo Anatole. Un hombre escribe en inglés el libro que otro hombre escribió en francés. Un libro se hace en soledad, pero, cuando el traductor escribe su libro, lo escribe con las palabras de otro hombre que no está en la habitación. Aunque sólo haya un hombre en la habitación, hay dos hombres que hablan en la habitación: cada uno habla en una lengua para querer nombrar las mismas cosas. El traductor se convierte en una sombra, fantasma del hombre que inventó las palabras que ahora inventa el traductor. La traducción es un caso de suplantación de identidad: por decirlo con una palabra inglesa, es un caso de impersonation. Impersonation significa suplantación, el acto de hacerse pasar por otro" 3 .

La mirada que aquí proyecta Navarro sobre el acto de la traducción describe un movimiento de identidad, un desplazamiento de las cualidades del escritor, o bien un descubrimiento de la figura del traductor, que pueden hablarnos de diversas cuestiones. De dos sujetos, de uno que suplanta a otro; del traducir, de un modo de lectura que implica una significativa modificación del texto, tanto como para cambiar todas sus palabras... Pero, sobre todo, nos interesa que nos está hablando de cómo creemos leer a uno cuando en realidad estamos leyendo al otro. El traductor es transparentado en el proceso de la lectura, aunque su labor sea opaca. Se ha hecho pasar por otro, y le hemos creído: leemos a Mallarmé. Pues bien, gracias a la lectura de este texto se nos ocurre que también podemos pensar en la confusión de dos

\footnotetext{
Vid. FERRETER MORA, J.: Diccionario de Filosofía. Nueva edición actualizada por la Cátedra Ferrater Mora bajo la dirección de Josep-Maria Terricabras, Círculo de Lectores. Barcelona, 2001, vol. IV, págs. 3415-3416.

2 BOZAL, V.: "Orígenes de la estética moderna", enAA. VV.: Historia de las ideas estéticas y las teorías artísticas contemporáneas, vol. I, Visor, Madrid, 1996, pág. 29.

3 NAVARRO, J.: "El cazador de coincidencias. Prólogo", en AUSTER, P.: El cuaderno rojo, Barcelona, Anagrama, 1994. págs. 16-17.
} 
tipos de sujeto ante una obra de arte. De hecho, en el conflicto de la indiferenciación entre ambos radican no pocas contradicciones, entendemos, del sistema y de muchos de los discursos artísticos contemporáneos. Como decíamos, dos sujetos: a uno lo llamaremos moderno y al otro posmoderno. Al sujeto moderno lo hemos definido como un sujeto burgués, asentado sobre la confianza en la razón como instrumento para comprender el mundo, el sujeto del arte tal y como lo comprendemos dentro del paradigma de la modernidad: el sujeto de la contemplación estética, un intérprete, un espectador-creador. Este sujeto estético viene aquí dado como tal en función de su relación con un objeto estético: una obra de arte. Hay otro sujeto, al que también se le llama sujeto estético, que, sin embargo, pertenece a nuestra condición (postmoderna) actual. Este sujeto existe, claro, en función de otro objeto estético, que en este caso es un mundo espectacularizado, el irreconocible escenario de la banalización generalizada bajo el paradigma retórico de la imagen. El primer sujeto se sitúa frente a la obra de arte y desarrolla entonces una relación estética a partir de ella. El segundo sujeto habita un mundo estetizado.

Vista la cuestión desde tal perspectiva, estaríamos, por seguir con el término de Navarro, ante un caso de impersonation, pues a estos dos sujetos se les nombra con las mismas palabras: sujeto estético. La confusión entre uno y otro es una constante en el fenómeno artístico de nuestro tiempo, aunque ambas figuras están determinadas por circunstancias muy diferentes, y sus posibilidades y expectativas no pueden equipararse. El hecho de hacerlo indica el deslizamiento de unos paradigmas de apreciación concretos hacia territorios que ya no responden a los valores iniciales que los fundaron. Nos encontramos, así, con el hecho, constante y perfectamente naturalizado, de que se enjuician obras actuales desde criterios propios de otro espacio cultural, pretérito e inadecuado respecto al objeto que abordan. Es por ello que, cuando hablamos de sujeto estético, se hace fundamental distinguir a cuál de estas figuras nos estamos refiriendo, pues de sus características y de la pertinencia de su actuación (o la ausencia de ella) depende la lógica del discurso que los implica. Evidentemente, la confusión se presenta porque hay un proceso que la ha producido. $Y$ ese proceso hemos aquí de discernirlo, pues afecta de modo claro a las cuestiones que centran nuestra propuesta: habremos de distinguir las características de ambos sujetos, uno procedente del otro, pues, como decimos, si bien los une una relación genealógica, sus diferencias son notables. Intentemos, pues, reconocer la historia de su rostro, que es el nuestro.

La modernidad ha producido ambos sujetos. Ello es posible porque ella misma es múltiple, se ha dado conforme a distintos modos en diferentes esferas de civilización. La propia concepción temporal con la que se entiende el devenir de la realidad es deudora de esta escisión en el proceso moderno. Este aspecto, revelador de otros muchos, lo explica Matei Calinescu del siguiente modo: 
[...] "La modernidad en el sentido más amplio, tal y como se ha hecho sentir históricamente, está reflejada en la irreconciliable oposición entre el conjunto de valores que corresponden a 1) lo objetivado, tiempo socialmente mensurable de la civilización capitalista [el tiempo como una comodidad más o menos preciosa, vendida y comprada en el mercado], y 2) lo personal, subjetivo, dureé imaginativa, el tiempo privado creado por el desdoblamiento del 'yo'.Esta última identidad del tiempo y del yo constituye el fundamento de la cultura modernista" 4 .

El profesor Calinescu segrega unos valores que, dice, serán los que den fundamento a la cultura. Por tanto, segrega esa cultura de "lo objetivado, tiempo socialmente mensurable de la civilización capitalista". Queremos hacer ver la importancia de esta operación para comprender, precisamente, el proceso cultural de la modernidad, pues, de hecho, aquí queda claro cómo podemos hablar no de una sino de dos modernidades: las que se desprenden de la distinción citada. Y veremos que nuestra condición estética actual es el resultado del enfrentamiento entre ambas. La destitución práctica del sujeto emancipado y libre formulado por el proyecto ilustrado -el que, según Kant, dotaba al hombre de "la libertad de hacer siempre y en todo lugar uso público de la propia razón"5- es un hecho corroborado día a día a lo largo de casi tres siglos. El gran cambio social que, entonces, se produce, radica en que la modernidad económica y social, el capitalismo industrial y sus desarrollos, habrían producido el efecto de ir relegando ciertos aspectos de la vida a un territorio acotado y retirado de la estructura social básica. La cultura ha pasado de su formulación como un fundamento de códigos y valores compartidos, a convertirse en una especie de anexo a la centralidad del mercado. $Y$, sin embargo, parece lo contrario.

Asomarse hoy a la ciudad, o volverse hacia el interior(ismo) de casa, significa reconocer innumerables códigos estéticos que organizan nuestra relación con las cosas, incluso nuestros valores y circunstancias más personales (la anorexia como patología eminentemente posmoderna podría servirnos de dramático ejemplo). Parece que esa gran discriminación entre sociedad y cultura se hubiera, sin embargo, resuelto hoy mediante una popularización general de la cultura, tal y como predicaron las vanguardias a principios del siglo XX. Así pareció entenderlo Daniel Bell en Las contradicciones culturales del capitalismo (1976), cuando afirmaba que:

[...] "lo que existe hoy es una radical disyunción de la cultura y la estructura

\footnotetext{
4 CALINESCU, M.: Cinco caras de la modernidad. Modernismo, vanguardia, decadencia, kitsch, posmodernismo, Madrid, Tecnos, 1991. págs. 16-17.

5 KANT, I.: "Respuesta a la pregunta: ¿Qué es la llustración? (1784)", en AA. VV.: ¿Qué es la llustración?, Madrid, Tecnos, 1999, pág. 19.
} 
social, y tal disyunción ha preparado el camino para revoluciones sociales más directas".

Esta nueva revolución ya ha comenzado en dos modos fundamentales. Primero, la autonomía de la cultura, lograda ya en el arte, está pasando ahora al terreno de la vida. El temperamento posmodernista exige que lo que antes se representaba en la fantasía y la imaginación sea ahora actuado en la vida. No hay ninguna diferencia entre el arte y la vida. Todo lo que se permite en el arte se permite también en la vida.

En segundo lugar, el estilo de vida practicado antaño por un pequeño cenáculo, fuese la máscara vital de un Baudelaire o la cólera alucinatoria de un Rimbaud, es ahora imitado por "muchos" (una minoría de la sociedad, sin duda, pero no obstante grande en número) y domina la escena cultural. Este cambio de escala dio a la cultura del decenio de 1960 su especial oleaje, junto con el hecho de que el estilo de vida bohemio, antaño limitado a una minúscula élite, ahora es puesto en práctica en la gigantesca escena de los medios de comunicación"6.

Sin embargo, podemos decir que, pese al atractivo del diagnóstico de Bell en 1976, sigue habiendo una clara distinción entre el arte y la vida. Buena prueba de ello es la profunda grieta que separa el arte contemporáneo del público general. De aceptar el punto de vista de Bell, habríamos de concluir que esa pretendida indistinción se ha producido bajo la forma de una tremenda banalización del arte en su sentido moderno, hasta el punto de vaciar totalmente de significación unas actuaciones estéticas que, precisamente, fundamentaban su razón de ser en su carácter intelectual. Bell relata cómo la concepción racionalista, empírica y pragmática del mundo que define la mentalidad burguesa llegó, a mediados del XIX, a dominar toda la estructura social, tanto tecno-económica como cultural. Para ser resistida, primero, y modificada, después, a partir del esfuerzo heroico de diferentes vanguardias artísticas. Pero una cosa es el descrédito generalizado que experimentó esa visión burguesa del mundo, en sus aspectos socialmente más conservadores y puritanos, y otra diferente es la culminación de una especie de culturización en masa de la sociedad deducida de la mimetización de gestos célebres. Si bien, desde mucho antes, por ejemplo Schlegel podía abogar por "aniquilar lo que llamamos orden"7 o declarar que "la diligencia y el provecho son los ángeles de la muerte que con espada de fuego impiden al hombre volver al Paraíso"8, una mirada actual al mundo entorno nos da

6 BELL, D.: Las contradicciones culturales del capitalismo, Madrid, Alianza, 1996, págs. 62-63.

7 SCHLEGEL, F.: Lucinde (1799), cit. INNERARITY, Daniel: Hegel y el romanticismo. Madrid, Tecnos, 1993, pág. 91.

8 Ibídem. 
un índice de la distancia que nos sigue separando de la realización de tales los sueños modernos.

Como vemos, la cuestión revela variados síntomas, pero los iremos atendiendo poco a poco. Lo que aquí nos concierne ahora es constatar, con tantos antes, una sistemática separación entre cultura ( $y$ el arte en ella) y sociedad postmodernas cuya consecuencia es nuestro presente, un proceso de segregación que oculta toda una ideología de la producción.

\section{SuJETO MOdERno E IDEALISMO dE LA RAZÓN.}

Hemos comenzado atendiendo a la caracterización de lo que llamamos sujeto, para poder hablar de un sujeto estético en razón del cual articular nuestra calificación de un arte invisible. Y nos hemos encontrado con el problema de la escisión de ese sujeto en el desarrollo de su modernidad. Dos modernidades, la que objetiviza y racionaliza para mercantilizar, y la que reclama la atención a la condición humana del proceso, la que recuerda aquello de la emancipación, la que aspira a una intensidad vital que no le ofrece la planicie del sistema de masas. De masas: ahí podemos vislumbrar una de las claves de la cuestión. Porque, cuando la cultura moderna comenzaba a expresarse, cuando sus primeros mecanismos iniciaban su funcionamiento, el concepto de masa no tenía la misma significancia con que rige actualmente. Y, por supuesto, no determinaba la producción cultural. De hecho, podemos comprobar cómo la propia estética fue organizada en razón de un modo de apropiación del mundo que presupone una cierto modo de estar en él, un modo que no estaba al alcance de todos. Por supuesto, no al de las masas.

Ello es así porque estamos hablando de una situación, la del sujeto moderno ante el mundo, que sólo puede protagonizarse desde una posición de desvinculación con respecto a lo que se juzga. En esto, decimos, consiste la distancia crítica sobre la que se fundamenta nuestra concepción de la razón, y también nuestro modo moderno de acceder al arte. La distancia como estrategia racional, la que permite hacer objeto y hacer juicio, la que produce la ciencia para aprehender y para dominar el mundo... está definiendo un sujeto con entidad propia, autónoma. Esto requiere el abandono de instancias superiores a su capacidad de juicio, a la Razón: el Destino o la Providencia, como tales órdenes que escapan a su nuevo poder lógico, dejan de a ser tomados en consideración a la hora de entablar una relación de comprensión con el mundo entorno. Pero, en el ámbito estético (aunque no sólo en él, como se verá) otras instancias ideales y trascendentales, como la Belleza, continuarán, sin embargo, plenamente vigentes e incuestionadas hasta finales del XIX.

${ }^{9}$ La belleza se convierte durante el romanticismo en una idea esencial para comprender el mundo y el hombre. De hecho, se reconoce como aquello que permite pensar al espíritu del hombre en analogía con la natu- 
Incluso, la belleza, por ejemplo, se verá reforzada en su significancia ideal durante la exaltación romántica de la naturaleza ${ }^{9}$. Y es que la estética se había instituido como disciplina con la que dar cuenta de aquello que la Razón no acertaba a objetivar, esto es, a subsumir bajo el paradigma científico. Por eso se formula como una teoría de la sensibilidad.

Lo que queremos subrayar es que se reconocían amplios territorios de la subjetividad que no eran iluminados tan fácilmente mediante la trama racionalista, y ello crea no pocas escisiones en el seno de una cultura que se pretendía esencialmente humanista (pese a muchos de sus efectivos desarrollos posteriores). Si la estética se había desligado de la filosofía había sido, precisamente, para poder atender cuestiones que dependían de un tipo de experiencia, la experiencia sensible, cuyo tratamiento filosófico tradicional no respondía a las inquietudes que se planteaban. Lo cual deparará ostensibles fluctuaciones en el devenir del arte, que oscilará entre una necesidad de conceptualización, derivada de la general racionalización de las condiciones generales de existencia, y una tendencia al desarrollo del yo individual que se rebela contra las estructuras, prejuicios y convencionalismos sociales a través de la expresión artística, queriendo investigar así los planos del ser a los que la objetivización del mundo había dejado sin espejo en el que reconocerse.

De esta forma, los campos existenciales que habían venido justificando a la teología se van a secularizar como resultado de su iluminación. Sin embargo, el hombre continuará proyectándose en instancias ideales, lo cual propiciará, pese al profundo cambio civilizatorio que se está experimentando, el mantenimiento de algunos referentes más allá del presente moderno. Ello explica cómo la idea de Progreso se constituye en una especie horizonte trascendental y, además, universal, aplicable a todos los campos. Por ejemplo al arte:

"[...] la vieja y dilatada querella entre los antiguos y los modernos no adquirió impulso hasta que el racionalismo y la doctrina del progreso ganaron la batalla contra la autoridad en la filosofía y las ciencias. La Querelle comenzó propiamente cuando algunos autores franceses de mentalidad moderna, conducidos por Charles Perrault, pensaron que era apropiado aplicar el concepto científico de progreso a la literatura y el arte". ${ }^{10}$

raleza, en un intento de recuperar una situación en el mundo que ha sido arrebatada por el mecanicismo racionalista y la lógica de dominación que implican también los cambios civilizatorios de la modernidad. Las palabras de Hölderlin, dirigiéndose a los grandes pensadores de la era moderna, puede ilustrar ajustadamente lo que queremos expresar:

"[...] con vosotros he llegado a ser tan racional, he aprendido a diferenciarme radicalmente de todo lo que me rodea, y ahora estoy separado en el bello mundo, he sido expulsado del jardín de la naturaleza, donde crecía y florecía, y me agosto al sol de mediodía. Un dios es el hombre cuando sueña, un mendigo cuando reflexiona..." Cit. INNERARITY, D.: Op. Cit., pág. 87.

10 CALINESCU, M.: Op. Cit., pág. 37. 
Esta asociación de modernidad y refiguración del idealismo era la conjugación usual de un tiempo de transformaciones en el que los nuevos valores habían de germinar en un terreno roturado por decenas de siglos de cristianismo. Podemos comprobar, pues, cómo se mantiene un fuerte idealismo artístico -del que, por cierto, parece somos cumplidos herederos- a través de los cambios que se producen. De nuevo, el romanticismo es la mejor prueba de ello. Y este proceso, sin duda, tiene unas razones de ser. Una de las más significativas puede encontrarse en el hecho de que, a través de la tradición ${ }^{11}$, las instancias simbólicas de trascendencia siempre han venido sirviendo para articular la comunidad social. La nuestra es una cultura de ascendente judeo-cristiano en la cual muchos eventos y esquemas de comportamiento han sido siempre representados y empleados como aparato social de trascendencia, algo, como saben los antropólogos y los sociólogos, común a muchos otros modelos civilizatorios, pero particularmente llamativo en Occidente si atendemos a los modelos de concepción histórica y humana que se legitiman en aras de la Razón. La necesidad de estos modelos modernos es también atendida por Daniel Bell, quien lo explica claramente cuando escribe que:

[...] "toda sociedad trata de establecer un conjunto de significados mediante los cuales las personas pueden relacionarse con el mundo. Estos significados especifican un conjunto de fines o, como el mito y el ritual, explican el carácter de las experiencias compartidas o tratan de las transformaciones de la naturaleza mediante los poderes humanos de la magia o de la techné. Esos significados están encarnados en la religión, la cultura, y el trabajo. La pérdida de significados en estos campos origina un conjunto de incomprensiones que la gente no puede soportar, y acucian, con carácter de urgencia, a la búsqueda de nuevos significados, para que todo lo que queda no sea una sensación de nihilismo o el vacío"12.

En nuestro caso, no estamos hablando necesariamente de religión. El lugar del imaginario colectivo que tantos siglos ocupó ésta, luego fue sustituido por otros conceptos: Libertad, Utopía, Democracia, etc. vinieron a relevar a Dios, pero básicamente para continuar gestionando unos flujos de energía social que no podían quedar sin sentido. Según Durkheim, la religión no deriva de una creencia en lo sobre-

\footnotetext{
11 Con gran agudeza, Daniel Bell hace notar cómo la instancia religiosa ha ejercido en la sociedad occidental la función, entre otras, de proporcionar una continuidad cultural con el pasado: [...] "La cultura, cuando se fundió con la religión, juzgó el presente sobre la base del pasado, y brindó la continuidad de ambos mediante la tradición" (Op. Cit., págs. 152-153). La tradición funciona como fundamento legitimador del presente en razón de un pasado común, reconocido por todos. Un pasado religioso.

12 BELL, D.: Op. Cit., pág. 143.
} 
natural o los dioses, sino de una división del mundo entre lo sagrado y lo profano ${ }^{13}$. De esta forma se entiende la sacralización de las figuras del Progreso: las ideologías revolucionarias pueden, al menos en sus inicios, ser consideradas así. Resulta importante, entonces, tener presente cómo la cualidad de trascendencia ha permitido que el sujeto se sienta partícipe de una comunidad. Una comunidad de culto, una comunidad ideológica, o nacional, o política, de clase... El caso es que el sujeto moderno se sentía partícipe de la Historia, de un proyecto común por el que se luchaba o no, pero en el que se sabía inmerso. La Historia tenía un sentido. Pero, ¿podríamos decir lo mismo del sujeto postmoderno?

\section{EL SUJETO POSMODERNO Y EL ESPECTÁCULO DEL MUNDO.}

Pensemos en las instancias que articulan nuestras comunidades actuales. $Y$ observemos cómo lo que antaño eran entidades simbólicas de trascendencia, que se alimentaban directamente de la implicación de la subjetividad individual en un proyecto colectivo a gran escala, hoy han quedado relegadas a grupos políticos y, en menor medida, religiosos que socialmente son cada vez más marginales, pese al incremento espectacular de su representación mediática. En cuanto nexos del individuo con la colectividad, podemos considerarlos meros productos nostálgicos, residuales de unas formulaciones ideales. Esa gran capacidad de cohesión social a que hemos hecho referencia se debe ahora a otros mecanismos, a otros intereses, y éstos se refieren a razones cuyo signo resulta muy diferente: mucho más utilitario y contingente. Podríamos decir que el interés del sujeto postmoderno no trasciende su presencia, sino que se refiere siempre a sí mismo, del mismo modo que la historia que se contempla es la de la propia expectativa de vida. Cuando la participación política o la comunión religiosa han dejado paso al campo de fútbol o a la compra ritual y compulsiva en el centro comercial, podemos sospechar que algo ha cambiado en el sujeto que protagoniza la secuencia. ¿Ya no se siente partícipe del mundo el sujeto postmoderno?

Asomémonos a su mundo. Observemos cómo está determinado más que nunca por unos valores fundamentalmente economicistas derivados de la estructuración de las sociedades occidentales en función del neocapitalismo que les da fundamento de acción y existencia. Este cambio social respecto a estadios históricos anteriores ya fue previsto, entre otros, por Hegel, cuya visión al respecto contempla el profesor Daniel Innerarity en su libro Hegel y el romanticismo (1993). En él, señala cómo:

[...] "la diferenciación de la esfera económica que ha tenido lugar en la modernidad ha conducido a que este sistema de acción imponga su propia lógica sin

13 Cit. BELL, D.: Op. Cit., pág. 151. 
límites. El tráfico mercantil es un ámbito éticamente neutralizado para la persecución estratégica de intereses privados y por eso no puede ser ámbito de integración. Esta reciprocidad sin espíritu configura unos vínculos inconscientes en los que el individuo no se puede reconocer. De ahí la despreocupación por la totalidad que se apodera del alma del ciudadano y que Hegel detecta con especial clarividencia: "La parte que se confía a cada uno en la totalidad despiezada es tan pequeña en relación con el conjunto que el individuo no tiene por qué conocer esa relación ni tomarla en cuenta".

De estos supuestos resulta la mecanización de la política, de la que se apodera una mentalidad calculadora"14.

La desvinculación del sujeto respecto al conjunto llevará, como hemos comprobado con el tiempo, a la propia disolución de la idea de comunidad tal y como se ha venido comprendiendo en la modernidad. A lo sumo, esta idea subsiste hoy en un plano simbólico, esto es, meramente ritual, como un monumento para recordar lo que ya no está, pero que contribuye a mantener lo que hay. La comunidad ha sido suplantada por el producto de los mecanismos industriales de producción de realidad: un mundo espectacular, un gran show para todos. Los órganos de reflexión, debate, participación o acción social, antaño fundamentos ideales del sistema democrático moderno, han quedado sustituidos por una suerte de actividades de ocio que no contemplan tales funciones y, si lo hacen, es bajo la forma de su sistemática teatralización, ficcionalización y banalización. Como un poco más adelante recuerda Innerarity, Hegel también intuyó un desarrollo semejante, e incluso pensó cómo afrontarlo:

[...] "Por eso postula Hegel una mediación intersubjetiva para superar esa espontaneidad elemental que adopta la forma de un privatismo de los intereses. Es necesario subsumir los antagonismos en la esfera de una eticidad viva, precisamente en este momento en el que, frente al espejismo de una liberación individual, "las ideas morales pueden encontrar un sitio en el hombre", de tal modo que "las constituciones que sólo garantizan la vida y la propiedad dejan de ser consideradas las mejores". Solamente puede superarse la paradoja de una libertad que termina creando un aparato de terror (der ängstliche Apparat) si la libertad se entiende como configuración de una comunidad política, si se abandona la atomización de subjetividades hostiles a favor de una solidaridad compatible con la libertad individual"15.

\footnotetext{
14 INNERARITY, D.: Op. Cit., págs. 70-71.

15 Ibídem., pág.71.
} 
Evidentemente, a Hegel se le ha hecho poco caso en este sentido, y la máquina del mundo nos integra perfectamente en su funcionamiento, a cambio de obviar cualquier relación de intervención significativa por nuestra parte. Por eso, si nos asomamos, como decíamos, al mundo de un sujeto postmoderno, no encontraremos tal "comunidad política", ese privilegio de las mediaciones que valoraba en filósofo alemán: veremos, más bien, un territorio vital trazado por unas necesidades de consumo y acotado por unos ritmos perfectamente delimitados. $\mathrm{Y}$, si buscamos proyecciones de este sujeto en la comunidad en la que vive, incluso si rastreamos algún indicio de preocupación por un futuro común... podremos comprobar que, realmente, ésas no son prioridades de acción de nuestro sujeto. La antigua conciencia del sujeto social como partícipe de la realidad de su mundo ha quedado relegada, repetimos, a ciertos rituales de representación democrática o a actuaciones particulares respecto a problemas concretos, como sería el caso de las ONGs. El sujeto postmoderno, de modo genérico, vive para sí porque su conciencia de ser miembro de una comunidad social se ha reducido a una mínima expresión: podemos concluir que no se reconoce como partícipe de la realidad, de una realidad comunitaria y universal en el sentido moderno del término. Resulta, pues, lógico advertir que la naturaleza del sujeto postmoderno no es tanto la del actor como la del espectador del mundo.

Esta situación corresponde a un proceso de desmitificación cultural que ha producido el desbancamiento del pensamiento idealista, en pos de una neta pragmatización de la existencia bajo el signo del rendimiento económico. Muy poco que ver, por tanto, con el tipo de capitalismo que había producido al sujeto moderno como antítesis de la estructura social vertical proveniente del feudalismo medieval. Si, en un momento histórico dado, el idealismo fue un modo de pensamiento que propició la proyección del hombre más allá de su existencia individual, posibilitando la concentración de una potencia social encauzada hacia la consecución de los grandes cambios sociopolíticos que todos conocemos, la crisis de la ideologías que hemos presenciado en la segunda mitad del siglo XX ha puesto muy difícil al sujeto postmoderno el establecimiento de órdenes globales de valoración que le resulten socialmente convincentes. $Y$ esto, como hemos insinuado antes, produce una inhibición respecto a la capacidad de acción y participación en la comunidad cultural, en la sociedad. Este proceso actual fue detectado de forma temprana por el crítico Irving Howe, quien en su Mass Society and Postmodern Fiction, texto publicado en 1959, explica el cambio a la condición postmoderna en función de una serie de fenómenos vinculados al surgimiento de una sociedad de masas. Estamos refiriéndonos a procesos tales como la pérdida de poder de "centros tradicionales de autoridad, como la familia", una progresiva indistinción de clases sociales, una patente pasividad como actitud social general, o la propia transformación del hombre en su consumidor, "él 
mismo producido en masa como los productos, las diversiones y los valores que absorbe"16. Todos estos cambios se corresponden con una inevitable consecuencia: la resituación del sujeto frente al mundo, su reubicación existencial a modo de espectador, como indicamos antes. El sujeto agente de la modernidad ya no encuentra sentido a su concepción del espacio comunitario como lugar de acción pública. En otros lugares, en cambio, aparecen y se asientan estructuras de comportamiento que tejen el entramado que hoy llamamos nuestro mundo, en el cual grandes dispositivos mediáticos administran las posibilidades de recepción de su sujeto correspondiente, reiteramos marcadamente pasivo respecto a su antecesor moderno. Ello viene dado, entre otros factores, porque no parece ahora existir una necesidad de actuar colectivamente: ¿actuar dónde, cómo y respecto a qué? Podríamos decir que la respuesta se muestra taxativa: ningún programa, ningún ideal, ningún proyecto de futuro más allá de la seguridad de un plan de pensiones.

\section{MODOS MODERNOS Y MODOS DESPRECIADOS DE FRUICIÓN ESTÉTICA.}

La cuestión que se nos plantea en este paisaje que nos hemos permitido esbozar afecta a los modos en que el sujeto se hace con la realidad -y, por tanto, cómo concibe la ficción. Estamos hablando, entonces, de aproximarnos a ciertas condiciones de la representación en la actualidad, ya que su estudio nos permitirá comprender adecuadamente el carácter del arte contemporáneo que se desarrolla a través de la configuración de lo que tipificamos como arte invisible.

Partimos, pues, del hecho claro de que nos encontramos con la figura del sujeto estético en un mundo modificado respecto a la modernidad. Hemos visto cómo este sujeto se resolvió inicialmente en ella mediante su oposición a una cultura dominante, es decir, se definió como minoría revolucionaria. Pero ahora lo hallamos habitando un mundo en el que, otra vez en palabras de Howe, "la nueva sensibilidad es un éxito desde su mismo comienzo. El público de clase media, ansioso de emociones y humillaciones, le da la bienvenida: también lo hacen los mass-media...; y, naturalmente, aparecen intelectuales con teorías cómodas"17. La accesibilidad del producto se convierte en un requisito necesario dentro de una cultura que ahora se conduce, de modo evidente, mediante una lógica mercantil. Retomamos la pregunta: ¿podemos decir con propiedad que estamos aquí ante un sujeto estético? Pues, de ser así, ¿qué lugar queda para la cultura entendida en su sentido moderno de van-

\footnotetext{
16 HOWE, I.: "Mass Society and Postmodern Fiction", en Partisan Review, n² 26, 1959. Cit. CALINESCU,M.: Op. Cit., pág.138.

17 Ibídem.
} 
guardia intelectual? Si hemos de guiarnos por el share que indica la aceptación en el mercado de las propuestas, esto es, de la ofertas que se exponen al consumo, esa idea moderna de cultura aparecerá, simplemente, como una rareza museificable. Lo cual, pensamos, no representa en modo alguno la realidad de una situación que, no lo olvidemos, viene producida por un mercado massmediático (en el cual aún no concluye el mundo). No, la cultura postmoderna se pliega en numerosos planos que no deben confundirse.

De tal forma que podemos descubrir por un lado una banalización sistemática de los modelos intelectuales más críticos, de cara a la distribución masiva de sus sucedáneos consumibles, y por otra la exacerbada intelectualización de actividades que habían proclamado su vocación universal, como por ejemplo el arte contemporáneo. El resultado de ese proceso es una marcada y progresiva desarticulación de la capacidad crítica y subversiva de unos modos artísticos que surgieron desde una clara y fundamental vocación de participación en la praxis vital del mundo. De ello se sigue una individualización del sujeto respecto a su propia capacidad de intervención social, la cual hemos mencionado ya cómo experimenta una regresión muy significativa. Por eso, si de referirse a un sujeto estético se trata, podemos hablar de un sujeto paciente definido por su capacidad de desear y satisfacer sus deseos, esto es, de consumir. Empleando una terminología artística, diremos que estamos ante la modificación del moderno espectador-creador, que deviene en un tipo de espectador-consumidor.

Sin embargo, hemos aquí de especificar que estos procesos suelen venir descritos con un cierto tono apocalíptico que, aún desde la profundidad del análisis y lo certero de los diagnósticos, es cierto que en muchas ocasiones nos hacer obviar caras del fenómeno que se muestran muy interesantes en el momento de querer tanto comprender sus razones como vislumbrar sus posibilidades.

Desde un particular y, ciertamente, desvelador punto de vista, Gilles Lipovetsky habla de una inédita ampliación de la libertad del sujeto bajo estas condiciones. En efecto, situándose de modo explícito frente a conocidas interpretaciones, de muy fundado pesimismo ante el devenir del imaginario actual -las dadas por Jean Baudrillard o Jean-François Lyotard pueden servir de ejemplo- este autor establece una clara relación de continuidad entre modernidad, postmodernidad e individualismo, para reconocer en él un particular y muy significativo giro en la matriz democrática que antepondrá el criterio de libertad al de igualdad:

[...] "Tocqueville decía que los pueblos democráticos mostraban un `amor más ardiente y más duradero por la igualdad que por la libertad': tenemos derecho a preguntarnos si el proceso de personalización no ha modificado seriamente esa prioridad. Indiscutiblemente la exigencia de igualdad continúa desplegándose, pero hay otra demanda más significativa, más imperativa 
aún: la de la libertad individual. [...] En la actualidad se toleran mejor las desigualdades sociales que las prohibiciones que afectan a la esfera privada; se consiente más o menos el poder de la tecnocracia, se legitiman las élites del poder y del saber pero se es refractario a la reglamentación del deseo y de las costumbres. El cambio de tendencia en provecho del proceso de personalización ha llevado a su punto culminante el deseo de liberación personal, ha producido un cambio de prioridad en las aspiraciones; el ideal de autonomía individual es el gran ganador de la condición posmoderna"18.

El concepto que da la clave del pensamiento que desarrolla el autor en este libro es el de personalización. Su empleo es recurrente, porque con él se explica el proceso de individualización que ocupa el epicentro del seísmo que habría sufrido la idea de sujeto proveniente de la modernidad. Como decimos, este concepto se relaciona directamente con el proceso de liberación del individuo moderno respecto a instancias sociales superiores, con la subsiguiente reducción de la carga emotiva invertida en el espacio público. A la inversa, lo que se produce es una muy marcada priorización del espacio privado y sus intereses. Ya hemos visto cómo ocurrió tal cosa respecto a la religión, pero, en su transcurso hasta hoy, la modernidad haría lo propio con el otro gran catalizador social del sistema capitalista: el trabajo. Toda la ética del trabajo propia de la concepción protestante de la existencia se articula en torno a la idea del mismo como una proyección de la religión a un vínculo mundano, "una prueba, por el esfuerzo personal, de la propia bondad y valor" 19 , en palabras de Bell, quien concluye que "para el hombre moderno y cosmopolita, la cultura ha reemplazado a la religión y al trabajo como medio de autorrealización o como justificación -una justificación estética- de la vida". 20

$\mathrm{Si}$, en efecto, es la cultura la que ha reemplazado las anteriores instancias de proyección social del individuo, de cohesión comunitaria, la idea de "cultura" se torna, como estamos viendo, fundamental. El problema que ahora nos encontramos es que, como venimos sugiriendo desde el inicio de estas líneas, el término "cultura" se aplica con tal profusión que su significado se torna realmente ambiguo. Porque de esto que nos dice Bell podríamos, rápidamente, deducir que la vida del sujeto postmoderno es eminentemente cultural, lo cual nos puede confundir. Nos confundirá si pensamos en una clase moderna de cultura que se identifique con la noción de vanguardia crítica que precisamente se ha instituido como símbolo (del cual aquí

18 LIPOVETSKY, G.: La era del vacío. Ensayos sobre el individualismo contemporáneo, Barcelona, Anagrama. Barcelona, 2000, págs. 115-116.

19 BELL, D.: Op. Cit., págs. 151-152.

20 Ibídem. 
podemos comprobar su alto grado de equivocidad) de tal modernidad, como también hemos apuntado más arriba. Si pensamos en la relación entre esa cultura y la sociedad en la que ocurre, podremos volver a comprobar que a lo largo de eso que estamos llamando modernidad, ambas esferas no han ido, ni mucho menos, en consonancia.

Pero lo que nos puede resultar más interesante, a la vez que discutible, en la tesis de Bell es que emplea el término en una acepción amplia. Podríamos decir que muy amplia, lo cual, por una parte, le lleva a realizar unas generalizaciones que producen innegables malentendidos como el que acabamos de señalar. Más, por otra parte, su análisis nos pone en posición de hallar y comprender la separación, el hiato que venimos mencionando reiteradamente, entre esa cultura moderna y la praxis habitual de la sociedad. Un espacio de contradicción que define nuestro tiempo y se presenta bajo el nombre de cultura de masas. Como cuenta Umberto Eco:

[...] "La situación conocida como cultura de masas tiene lugar en el momento histórico en que las masas entran como protagonistas en la vida social y participan en las cuestiones públicas. Estas masas han impuesto a menudo un ethos propio, han hecho valer en diversos períodos históricos exigencias particulares, han puesto en circulación un lenguaje propio, han elaborado, pues, proposiciones que emergen desde abajo. Pero, paradójicamente, su modo de divertirse, de pensar, de imaginar, no nace de abajo: a través de las comunicaciones de masa, todo ello le viene propuesto en forma de mensajes formulados según el código de la clase hegemónica. Tenemos, así, una situación singular: una cultura de masas en cuyo ámbito un proletariado consume modelos culturales burgueses creyéndolos una expresión autónoma propia. Por otro lado, una cultura burguesa -en el sentido en que la cultura "superior" es aún la cultura de la sociedad burguesa de los tres últimos siglos- identifica en la cultura de masas una "subcultura" con la que nada la une, sin advertir que las matrices de la cultura de masas siguen siendo las de la cultura `superior"”21.

La figura de la cultura de masas nos permite entender la cuestión de manera que esa cesura entre sociedad y cultura, en principio tan extraña a la naturaleza humana, pueda encontrar su lógica de existencia.

Las palabras de Eco, y, especialmente, las expresiones que emplea, nos resultan clarificadoras. Pues Eco reconoce en la cultura burguesa de los tres últimos siglos una cultura "superior" (evidentemente, cuando aquí habla de burguesía se está refiriendo a una alta burguesía heredera de los valores aristocráticos de distinción

21 ECO, U.: Apocalípticos e integrados. Barcelona, Lumen, 1995, pág. 42. 
social y cultural, el tipo de burguesía que, por ejemplo, puede mostrarnos Buñuel en El ángel exterminador).

La distinción clasista a la que asistimos aquí es bien significativa. No sólo porque en ella se fundamenta todo el razonamiento que articula el autor en este fragmento -que, a su vez, pertenece a la introducción de Apocalípticos e integrados, en la cual justifica la necesidad y los modos del libro- sino debido también a que remarca la falta de correspondencia entre la procedencia del producto cultural y sus receptores. Ya que, si es, como así ocurre, admitido y asumido como propio por las masas, ese producto debe, necesariamente, haberse modificado en el proceso. $Y$ esa modificación, mantenemos, pasa por la desactivación, causada por diversos mecanismos, de la función socializadora del mismo. Por eso se puede consumir de manera privada, porque ha pasado a constituir un mero instrumento de evasión de la realidad, nunca de cuestionamiento y reflexión en torno a ella, que es para lo que había sido concebido en su origen. Pues tengamos en cuenta que, cuando estamos aquí hablando de producto cultural nos estamos refiriendo concretamente a una producción artística con vocación de transgresión de un orden dominante de valores respecto al cual se define.

La cuestión es que lo que nosotros, con Eco, estamos aquí entendiendo por cultura "superior" es el resultado de un desfase temporal que provoca una caducidad operacional del producto. La explicación es la siguiente. Hemos dicho que al arte de vanguardia, un fenómeno elitista y altamente especializado, como ya han subrayado muchos autores, se plantea como rebelión ante el esquema vital burgués que domina la cultura moderna. Sin embargo, es esa burguesía la que no tarda en apropiarse de tales manifestaciones artísticas para, a través de su posesión y de la exhibición de su accesibilidad a ellas, distinguirse del resto de la sociedad. Este fenómeno de cosificación de discursos artísticos fundamentalmente conceptuales es paradigmático del arte que ocupa nuestros días. Evidentemente, su neutralización como problema es directamente proporcional a su magnificación como arte. Ello resulta algo perfectamente natural en el devenir del arte contemporáneo, y nos revela su carácter profundamente paradójico. Nos revela cuán profundo reside el mito de l'art pour l'art en el imaginario cultural moderno y, como estamos comprobando, posmoderno. Un mito que coloca al arte en un lugar en extremo autónomo, esto es, separado del resto del mundo. En su Teoría estética (1970), Adorno hizo referencia a esta relación que la burguesía había establecido con el arte:

[...] "Sartre ha subrayado con razón que el principio de l'art pour l'art que desde Baudelaire había prevalecido en Francia (como en Alemania) sobre el ideal estético del arte como presión moral, fue recibido con gusto por la burguesía porque veía en él una forma de neutralización"22. 
Una forma de neutralización que se ha mostrado tan exitosa como rentable, podríamos añadir más de treinta años después de que escribiera el filósofo alemán. A través de la asimilación del arte como una actividad de sistemática autorreferencialidad, su proyección social y su capacidad transgresora se reducen a una serie de efectos retóricos destinados a darse y reconocerse siempre en y para el escenario que viene a mostrar su ficción, su inoperancia, por tanto, para afectar a lo real. Y se puede decir que el devenir del arte en este sentido no ha opuesto mucha resistencia al proceso. La actitud crítica de las vanguardias se ha convertido en modelo y academia irrenunciable, pero esta mirada se vuelve introspectiva, se refiere al propio arte, con lo cual, de modo implícito, se respeta la territorialización burguesa a la que haciamos referencia anteriormente. No se ha planteado seriamente, pues, el acceso a un proceso de universalización del arte, que habría supuesto una radical modificación del sistema cultural que sostiene el concepto vigente de distinción y territorialidad. Un ejemplo claro de esto puede encontrarse en las palabras de Charles Harrison, director de la revista Art-Language, cuando se plantea la efectividad de su célebre colectivo artístico. Pues, si bien asumía que todo arte conceptual debe aspirar a transformar no sólo la práctica del arte, sino sobre todo el sentido de lo público, reconocía muy limitados los logros de Art \& Language en tal empeño:

[...] "Realistamente, Art \& Language no pudo identificar ningún efectivo público alternativo que no estuviese compuesto de los participantes de sus proyectos y deliberaciones" 23 .

Y este ejemplo de inaccesibilidad al público desde la revolución artística puede considerarse paradigmático de la situación contemporánea del arte. Llegamos, por tanto, a la conclusión, anticipada en líneas anteriores, de que la vocación socializadora del arte de vanguardia deja de existir: la catarsis se reduce a evasión en su proceso de consumo ${ }^{24}$. La situación de escisión del arte como producto social responde, así, al nuevo sujeto narcisista que hemos descrito. Un sujeto que no tiene la necesidad de antaño respecto a su inversión, crítica o emocional, tanto da, en el espacio público. Al contrario, su priorización del ámbito privado vuelve insignificantes los aspiraciones de socialización que puede recibir por parte de instancias tales como el arte o la política. Quizás ésta sea una de las razones del retraimiento

22 ADORNO, T. W.: Teoría estética. Madrid, Taurus, 1989, pág. 310.

23 Cit. CROW, T.: El arte moderno en la cultura de lo cotidiano, Madrid, Akal, 2002, págs. 220-221.

24 En su Pequeña apología de la experiencia estética (1972), Jauss habla de la catarsis para designar "la experiencia estética fundamental de que el contemplador, en la recepción del arte, puede ser liberado de la parcialidad de los intereses vitales prácticos mediante la satisfacción estética y ser conducido asimismo hacia 
que el arte "de vanguardia" ha experimentado respecto a su inicial ambición popular. simplemente, esa cuestión ha dejado de importar. Este aspecto puede ser interpretado como un claro ejemplo de cómo se está respondiendo, desde la producción artística, a una postura por parte de la sociedad, que, en este caso concreto, ya no requiere discursos ni proyectos universalistas ni emancipadores.

Se puede, pues, comprender como síntoma de que se está funcionando desde parámetros eminentemente mercantiles. Digamos que el arte se representa a sí mismo como si fuese revolucionario, como si abrigase una intención transgresora, como si no tuviese conciencia de su actual cualidad, repetimos, escénica. Habita, en fin, una condición de impostura, una ficción, que ya no incumbe, como es lógico, tan sólo al plano representacional, sino que también se simula una eticidad que garantiza su "prestigio" intelectual y, por lo tanto, su rendimiento mercantil.

De cualquier modo, si bien esta cosificación del arte responde de modo manifiesto a un mecanismo mercantil, no se debe tan sólo a él. Bajo este proceso subyace la transformación de un sujeto estético que ahora prima unos valores por encima de otros, esos otros que ya no responden a las prioridades de su mundo. Si hablamos de una modificación tal del arte, sigamos haciéndolo, pues, de la del sujeto al que éste se debe. En El fin de la modernidad (1985), el filósofo italiano Gianni Vattimo recurre -en una línea que vuelve en la actualidad a cobrar vigencia a partir del nuevo "descubrimiento" de fenómenos como el terrorismo o la lógica de la destrucción ${ }^{25}$ - al empleo del concepto de nihilismo para hablar de la situación del hombre en la actualidad. El término, al menos en la acepción con que lo usa Vattimo, proviene de Nietzsche, y hace referencia a su célebre diagnóstico de "muerte de Dios". Con la muerte de Dios, lo que se está nombrando es la desvalorización de los valores supremos, y Vattimo relaciona esta mirada con la que efectúa Heidegger respecto a la reducción del ser a valor, indicando previamente que ese valor de que habla el alemán quiere significar exactamente valor de cambio.

¿Cómo se puede establecer el vínculo entre ambos puntos de vista? A través, responde Vattimo, de la comprensión de que [...] "los que desaparecieron no son los valores tout court, sino los valores supremos, resumidos precisamente en el

\footnotetext{
una identificación comunicativa u orientadora de la acción". El sentido de utilidad vital implícito en este aspecto de la experiencia estética (desde que así lo comprendió Aristóteles en la tragedia), esa, digamos, cualidad instrumental de que nos habla, parece haber dejado de estar presente en el tipo de relación estética que se establece en la situación que estamos tratando. Vid. JAUSS, H. R.: Pequeña apología de la experiencia estética. Barcelona, Paidós, 2002, págs. 42-43.

25 Respecto a las lecturas de estos fenómenos como manifestaciones del nihilismo, vid. GLUCKSMANN, A.: Dostoievski en Maniatan, Madrid, Taurus, 2002. En él, el autor da cuenta de cómo la herencia llustrada ha preferido no ver los síntomas del proceso que ahora se plantea como peligrosa novedad global. Glucksmann mantiene, sin embargo, que desde hace dos siglos (precisamente desde Nietszche) se vienen pronosticando modos de tomar conciencia del mundo que, no obstante, siguen interpelando a las Luces: en palabras del autor, "el nihilismo debe y puede ser pensado desde la llustración".
} 
valor supremo por excelencia, Dios. Y todo esto, lejos de quitar sentido al concepto de valor -como lo vio bien Heidegger- lo libera en sus vertiginosas potencialidades: sólo allí donde no está la instancia final y bloqueadora del valor supremo Dios, los valores se pueden desplegar en su verdadera naturaleza que consiste en su posibilidad de convertirse y transformarse por obra de indefinidos procesos". 26

\section{Procesos.}

Más procesos que nosotros no observamos tan indefinidos en nuestro caso... Procesos de intercambio que, en las circunstancias que venimos describiendo, resultan, en efecto, intercambio comercial: a ello nos referíamos cuando decíamos que en el mundo del arte se está funcionando desde parámetros mercantiles. No se trata (solamente) de un proceso de mercantilización del objeto artístico, de reificación de lo simbólico, sino que estamos advirtiendo cómo ese fenómeno se remite a razones anteriores que abarcan la amplitud social y existencial del hombre, más allá del mero problema artístico. Esta efectiva sustitución del valor de uso (crítico, revolucionario) que había venido fundando la experiencia vanguardista del arte, por su valor de cambio, delata una escala mucho más amplia de transformación de las condiciones de civilización en las que se dan los fenómenos que estudiamos. En esta línea, ya hemos visto cómo la relación con la obra de arte se problematiza si se sigue planteando desde presupuestos modernos. Unos presupuestos que son los que tenemos en mente cuando hablamos de banalización estética, porque seguimos considerando estéticos ciertos modos muy particulares de aparición, despreciando otros, por tanto. Pero hemos de observar que tales modos despreciados, nos guste o no, constituyen algo muy presente, y vigente, en nuestro mundo, pongámosles el nombre que les pongamos. Esto, es claro, repercute en la representación artística, más exactamente en la manera como se accede a las producciones artísticas, pero exterioriza unas circunstancias culturales de carácter general: estamos hablando de una manera de comprender los espacios y los modos de relación intersubjetiva -de los cuales el arte sería (según el criterio moderno), territorio privilegiado- que muestran evidentes signos de transformación. No requerimos ni proyectamos las mismas inquietudes que antaño en los demás. Desde esa cápsula narcisista que Lipovetsky llama personalización, la relación con el otro se concibe, pues, de nuevo modificada:

[...] "Mientras el interés y la curiosidad por los problemas personales del Otro, aunque sea un extraño para mí, siguen en aumento (éxito de las revistas `del

26 VATTIMO, G.: El fin de la modernidad. Nihilismo y hermenéutica en la cultura posmoderna, Barcelona, Gedisa, Barcelona, 1986, pág. 25. 
corazón', de las confidencias radiofónicas, de las biografías) como es propio de una sociedad basada en el individuo psicológico, el Otro como polo de referencia anónima está abandonado igual que las instituciones y valores superiores" 27.

Y a la atención de estos intereses por parte del sujeto posmoderno no la podemos llamar propiamente cultura moderna. Por eso, insistimos, hoy hablamos de banalización y superficialización de las relaciones. Este fenómeno se suele explicar como efecto de que la progresiva socialización de la cultura en la modernidad -que por diversos autores ha sido narrada como un proceso de democratización- se produzca, a su vez, también como una separación de la cultura entendida en el sentido que le dimos al término cuando nos servimos de la figura de la distancia estética para explicarla. No se trataria, sin embargo, de defender una distinción general de niveles culturales high, middle o low. La, entre otros defectos, ineficacia de esta concepción del fenómeno ya fue rotundamente demostrada por Umberto Eco en Apocalípticos e integrados (1965). Quizás merezca la pena recordar su postura:

[...] "También en la esfera de los valores estéticos, debemos admitir que se ha verificado una especificación de niveles de tipo análogo [a la disparidad de desarrollo entre investigaciones teórica y práctica en el ámbito de la ciencia y la tecnología]: por un lado, la acción de un arte de vanguardia, que no pretende y no debe aspirar a una inmediata comprensión, y que lleva a cabo una experimentación sobre las formas posibles (sin que por ello deba necesariamente, aunque en algunos casos sea así, proceder ignorando los otros problemas y creyéndose la única creadora de valores culturales); por otro, un sistema de "traducciones" y de "mediaciones", algunas con intervalos de decenios, que por su modo de formar (con los sistemas de valores conexos) se encuentran a niveles de más vasta comprensión, integrados ya en la sensibilidad común, en una dialéctica de recíprocas influencias muy difíciles de definir y que sin embargo se instaura en la realidad a través de una serie de relaciones culturales de índole diversa. La diferencia de nivel entre los distintos productos no constituye a priori una diferencia de valor, sino una diferencia de la relación fruitiva en la cual cada uno de nosotros se coloca a su vez. En otras palabras: entre el consumidor de poesía de Pound y el consumidor de novela policíaca, no existe, por derecho, diferencia alguna de clase social o nivel intelectual. Cada uno de nosotros puede ser lo uno o lo otro en distintos momentos, en el primer caso buscando una excitación de tipo altamente

27 LIPOVETSKY, G.: Op. Cit., pág. 70. 
especializado, en el otro una forma de distracción capaz de contener una categoría de valores específica". ${ }^{28}$

Lo que nos interesa del punto de vista de Eco es cómo centra la diferencia de nivel en el sujeto, no en el objeto. Esto nos remite directamente al juicio de gusto ilustrado, y, como hemos dicho, a la necesidad de la distancia respecto al objeto para poder juzgarlo y apreciarlo. Así, Eco cuenta cómo quien disfruta con Pound también puede hacerlo con la novela policíaca, pero nosotros hemos entonces de preguntar: ¿qué ocurre si, a la inversa, ponemos esa poesía ante el lector de la novela?

Estamos ante un problema de capacitación del sujeto para situarse como tal ante un objeto y, entonces, hacerlo estético. Ello conlleva una clase de acción por parte del sujeto, un implicarse respecto al objeto, que se cifra, aún hoy, en el juicio de gusto. Pero nos encontramos con que el sujeto que hemos dado aquí en calificar como posmoderno no se hace cargo de esta acción de forma tan clara, tan diferenciada. Su interés por la imagen parece responder a un tipo de relación de carácter mucho más pasivo y generalista, ante unas imágenes mediáticas que, de nuevo en palabras de Eco, "en lugar de simbolizar una emoción, la provocan; en lugar de sugerirla, la dan ya confeccionada" 29 . ¿Dónde comprender, entonces, la formulación fundacional del juicio de gusto que sitúa la experiencia estética en el libre juego de la imaginación y el entendimiento del sujeto?

\section{RELACION Y CAPACITACIÓN.}

Por lo que llevamos visto, parece que en estos momentos se trataría, mas bien, de pensar en las condiciones de (im)posibilidad de espacios para el arte moderno cuando el sujeto posmoderno no reconoce ya su necesidad, al menos en cuanto que instancia social de representación. Las condiciones "habituales", las que han dado pie al inicio de este texto, las que corroboramos cada día, sitúan la modernidad del arte en su elitización. Al emplear este término, no estamos haciendo referencia a diferencias "de clase" social, como ocurrió en el pasado: hemos visto que lo que estamos calificando es una recepción especializada, que requiere de un proceso de capacitación para ejercerla. Tal proceso puede darse a priori, como tradicionalmente ha hecho nuestra cultura, mediante la formación del gusto de las personas a través de la educación; o puede darse, mantenemos nosotros, de un modo particular, en el propio proceso de relación con la obra. Por eso hablaremos de obras no como objetos de contemplación sino como operadores artísticos, como generadores de las

28 ECO, U.: Op. Cit., págs. 73-74 [La letra en negrita es del que escribe].

29 Ibídem., pág. 57. 
capacidades de relación sensible y cognitiva de que pueda disponer el sujeto en (o a partir de) su contacto con la imagen. Ello es lo que nos llevará a poder pensar en un proceso dialéctico que posibilita la efectiva didáctica de la obra como proceso de interpretación crítica de su entorno mediático.

Como estamos comprobando, el lugar que ocupa aún hoy un sujeto estético ante una obra de arte puede ser determinante de la misma. Sin embargo, parecen reclamarse para ello obras que impliquen el darse en el propio proceso de relación con ese sujeto. Un proceso que existe en un contexto definido por las condiciones actuales de producción de realidad mediante artefactos visuales de sofisticada retórica, esto es, por la necesaria naturalización de que son objeto las imágenes artificiales, incluidas por supuesto las del arte. Por lo tanto, la citada relación con la imagen por parte del sujeto se plantea como un proceso de producción de su propia condición de sujeto estético, de manera que esta transformación se opera en el transcurso de la obra. Digamos que la obra de la obra será el sujeto estético.

Con todo lo dicho podemos llegar al punto de plantear que se está buscando, desde el ámbito específico del arte, a un nuevo sujeto estético. El lector de Pound al que se refería Eco es un lector moderno. Pero nuestra propuesta respecto a un arte invisible implica el hecho de que el sujeto posmoderno, la fruición posmoderna, no tiene por qué ser necesaria (y excluyentemente) superficial y banal, sino que también puede desarrollar un modo dialéctico, como hemos indicado, respecto a la imagen ante la que se instituye como sujeto estético. $Y$ esa modificación compromete diversos planos que nos dan cuenta de lo valorable del trabajo artístico que estamos estudiando. Ante todo, estamos reconociendo un modo de articular una transgresión de los códigos de dominación social más naturalizados, lo cual nos vuelve a hacer pensar en categorías modernas del arte que fueron abandonadas hace tiempo en los museos y en las enciclopedias de historia del arte: ya hemos subrayado aquí la "muerte de la vanguardia" en su consumo masivo, en su repetición y asimilación mercantil.

Por otra parte, la búsqueda de este sujeto estético que habita territorios del mundo -un mundo que excede con creces las fronteras del mundo del arte- recordémoslo, supone una manera explícita de asumir una expansión de lo artístico que implica su disolución en lo estético. Este movimiento ha sido pregonado y considerado hasta la saciedad desde Hegel en adelante, pero nosotros creemos ver en el arte invisible una manifestación pragmática de ello que no se limita a tratarlo como tema o como problema de representación, sino que lo asume como condición de existencia de la obra en sí misma. Lo cual supone, evidentemente, el cuestionamiento de su propia condición como obra de arte, pero ese cuestionamiento no aparece como un fin de autorreferencialidad, tan al uso desde la modernidad del arte, sino como un inevitable y, reveladoramente, despreciable aspecto de un proceso que se dirige al sujeto como tal, más allá de su condición de espectador de arte. De mane- 
ra que la búsqueda de ese nuevo sujeto estético de que hablamos lo va a reconocer fuera de los límites de la convención artística.

Así pues, podemos deducir, según estas observaciones, que la diferenciación de sujetos que hemos tenido que plantear al principio para poder comprender la situación en la que trazamos nuestras indagaciones, no se muestra como una condición concluyente del proceso estético. Al menos en lo relativo a las obras que son objeto de estas líneas. Al contrario, tal diferenciación no parece existir para estas obras. $\mathrm{O}$, mejor dicho, éstas existen en función de la supresión de esa distinción. De forma que nos encontramos hablando de un sujeto que se asume como posmoderno pero que es tratado desde algunos intereses eminentemente modernos. Precisamente esos intereses que nos recuerdan la intencionalidad didáctica, socializadora, ideológica, activadora de una energía colectiva, de las vanguardias que más asumieron su capacidad de transformación social sobre la base del carácter público de la actividad artística ${ }^{30}$.

Por tanto, si en principio hoy podría parecer imposible pensar en una transgresión efectiva del orden que mantiene las condiciones del intercambio entre arte y espectador, estamos comprobando que una mirada atenta e intencionada descubre otros caminos aptos para esa empresa. Teniendo en cuenta, ya lo vimos, que tal sería uno de los intereses prioritarios de la actitud que funda el arte moderno, podríamos dejar de pensar en un acabamiento de ese aspecto: al contrario, lo que nos encontramos es una diversificación de las estrategias de aparición, derivada precisamente de la escisión consciente que hemos observado respecto a los modos artísticos que reconoce la institución-arte. Por eso, al tomar una vía divergente respecto a la modernidad "oficial" de las vanguardias históricas (más historificadas-museificadas-reificadas que nunca), el arte invisible ha de buscar a un sujeto "ajeno" a ese sistema de reconocimiento y apreciación.

Y buscarlo allí donde no esté, precisamente sujetado a la convención, atrapado en el territorio de lo dado, lo supuesto y lo indiscutible: la casa del arte. Buscarlo fuera del arte tematizado como arte en su correspondiente reserva cultural ajena al devenir ordinario de la praxis vital. Buscarlo donde ocurre ésta: en la calle, en el

\footnotetext{
30 Realmente, escribir hoy día en estos términos puede ser tomado como una exhibición de cierta "inocencia", quizás como una especie de "acto de fe" movido por la nostalgia de "tiempos mejores" en los que el arte se planteaba horizontes universalistas y utópicos. No obstante, partimos de la conciencia de que todos los "tiempos mejores" siempre son construidos para ser contados: son ficciones. Por tanto, tal nostalgia no tendría aquí razón de existir. Aquí se está leyendo el pasado para construir una lectura que dé un sentido al presente. $Y$ los términos a los que recurrimos nos son sugeridos por el propio devenir de una investigación que nos hace descubrir unas constantes en el transcurso del tiempo. Esto nos haría, al contrario, sospechar precisamente de la objetividad de tales suposiciones de "nostalgia", que se nos revelarían ahora como una postura ante el presente tan parcial como interesada en no recordar, es decir, ocultar, ciertas funciones del arte que pueden resultar molestas para el mantenimiento de una jerarquía de valores estéticos cada vez más apropiada a sus aplicaciones mercantiles.
} 
espacio público, siendo un elemento indistinto, una cosa más de ese cotidiano acontecer que llamamos vida. No podremos ya, entonces, hablar de un espectador que visita la obra de arte, sino de un ciudadano que habita la ciudad, que la recorre o pasea por ella, que casi siempre ve y a veces mira su infinito entorno de imágenes, su paisaje habitual... Y que, de pronto, se encuentra con un anuncio que le extraña: que le incita a replantearse qué es eso, qué dice. Pero sobre todo, cómo lo dice: pues así también se dice a sí misma esto que no dudamos en aceptar como la realidad, aunque ahora nos la encontremos, a través del arte invisible, revelada en ese anuncio extraño, esto es, desmontada como verdad y mostrada como constructo ideológico. Lo que, en fin, estamos describiendo es el proceso, eminentemente estético, de una capacitación del sujeto posmoderno, cifrado en la restitución al mismo de una condición de lector crítico de la superficie del gran espectáculo mediático del mundo. 